\title{
Modelling land management for ecosystem services
}

\author{
Luuk Fleskens • Klaus Hubacek
}

Received: 23 April 2013/ Accepted: 28 April 2013/Published online: 8 May 2013

(C) Springer-Verlag Berlin Heidelberg 2013

Ecosystem services encompass the multiple benefits that people receive from nature (Millennium Ecosystem Assessment (MA) 2005). The environment is managed to obtain a single or small bundle of ecosystem services at a given location often at the expense of other ecosystem functions and services and associated beneficiaries. In turn, decisions and practices of land owners and managers are driven by a wide variety of environmental, socio-economic and institutional driving forces (DeFries et al. 2004). Collectively, these decisions have wide ranging implications, through unintended side effects on the provision of ecosystem services, to regional stakeholders as well as people living further away.

The ecosystem services concept conceptualizes the 'complex links between ecosystems and human wellbeing' (Millennium Ecosystem Assessment (MA) 2005), recognizes that different stakeholders are likely to value ecosystem services differently and emphasizes the need for the decentralization of control over ecosystem service management (Hubacek et al. 2009). Affected stakeholders often try to influence land use and management practices using different strategies. One increasingly popular way to achieve this is through paying land owners and managers for the provision of such services. Payments for ecosystem services (PES) are designed to compensate social actors (e.g. land owners) for actions that increase the provision of so far non-traded services such as water purification or carbon sequestration (e.g. Wunder 2005; Pagiola and Platais 2007; Wunder et al. 2008). PES schemes

L. Fleskens ( $\square)$

Sustainability Research Institute, School of Earth and

Environment, University of Leeds, Leeds, UK

e-mail: 1.fleskens@leeds.ac.uk

K. Hubacek

Department of Geographical Sciences, University of Maryland, College Park, MD, USA are market-based policies with the intention to change behaviour towards providing multiple benefits beyond the current incentives provided by legislation, markets or other existing institutions (Mauerhofer et al. 2013).

The concept has become en vogue as an important integrating concept for a range of research disciplines and disparate interest groups. For example, public land managers and private land owners could see this as a potential opportunity for new and additional income streams from the provision of ecosystem services, especially in times of increasing restrictions on unfettered production, and thus potentially securing wider support for nature conservation (Brown et al. 2007; Goldman et al. 2008). Part of its practical appeal lies in its ability to help reframe the value of conserving nature, not as something that is extra or in conflict with human goals, but as an indispensable partner in achieving these (Hubacek and Kronenberg 2013).

The popularity of the ecosystem services terminology is also reflected in the scientific literature, with the number of articles about ecosystem services published per year rising exponentially from a mere 100 in 2005 to well over 1,000 since 2010, and the number of articles about PES growing from less than 5 in 2005-70 in 2010 and getting higher since (data from Web of Science). An important distinction is made in the PES literature between functional and management-oriented concepts of ecosystem services (e.g. Van de Sand 2012), with the latter offering a pragmatic perspective on using payments as incentives for management or land use practices that are expected to result in enhanced services rather than the service itself. Scales across which buyers and providers interact may also vary, from local to global. The dynamics of ecosystem services provision and use in time and space require better understanding, as well as methodological advancements to meaningfully characterize them. 
In this special section, we bring together 7 original papers which in different ways address land management decision-making and its impacts on ecosystem services. The majority of the papers stem from a special session on Modelling ecosystem services which was held in August 2010 at the Ecological Economics conference in Bremen, Germany, and which have since been further developed and refined.

Management and policy require an evidence base or at least some informed idea on how ecological systems respond to land use and management decisions and how incentives influence land managers. Computer models can help provide such information. Thus, this special section has two main aims:

1. To present case studies using formal computer modelling to show the interaction between land use, land management and different ecosystem services. The papers comprise a range of models applied in very different socio-economic and biophysical contexts starting from more conceptual modelling to complex integrated socio-economic and biophysical models.

2. To explore how modelling approaches can contribute to the design of PES schemes given different socioeconomic contexts and a diverse range of ecosystem services with diverse properties.

The first group of papers (mainly addressing the first aim) is covered by Qasim et al. (2013), Yeo and Huang (2013), Nainggolan et al. (2013) and Fleskens et al. (2013) (i.e. papers 1-4). Their important contributions are within the wider efforts of integration of socio-economic and biophysical factors into a modelling framework, by which they are able to show not only how decision-making of land owners and managers has influenced historical land use change, but also potentially forecast how agents respond to future driving forces.

Qasim et al. use logistic regression to explain for an alpine Himalayan Hindu Kush region how different geophysical and geographical factors influence land use changes at different altitudinal zones of district Swat, Pakistan, and how these influences have changed over the course of time by analysing land use maps of 1968, 1990 and 2007. While the analyses in the paper are based on geometric properties, their interpretation requires a clear understanding of the local development context. In fact, the paper shows that the analytical power of the modelling technique applied is sensitive to a correct zoning which aptly captures socio-economic dynamics. This type of approach is probably best suited to 'frontier-type' (here: elevation-based) land use change contexts, as criteria on which to distinguish change patterns in more complex land use systems could prove difficult to establish.
Yeo and Huang investigate drivers of secondary forest change using Mississippi (USA) as a case study. Forest changes are quantified at high spatial $(30 \mathrm{~m})$ and temporal (biennial) resolutions, using a time series of remotely sensed data between 1984 and 2007, and linked to various socio-economic, political and biogeophysical factors. Their results show that market conditions are the key predictor of forest disturbances, and also important for explaining spatial patterns of forest dynamics, which can change drastically on a short-term basis. Even though this paper does not explicitly make the link to forest-based ecosystem services, understanding forest changes and their trajectories is important for developing management and policy options.

Nainggolan et al. (2013) develop a typology of farmers, and by using responses to hypothetical scenarios, they demonstrate that land use and management choices are dependent upon socio-economic characteristics and background. By bringing in these agent-based characteristics, they seek to obtain a better understanding about the linkages between the characteristics of farmers, farm management and land use, with important implications for the landscape and associated ecosystem services. The authors conclude that recognizing the variety of land users is critical and that agri-environmental policies may, in order to be effective, require a combination of incentive-based measures, restrictive regulations and interventions that facilitate and encourage farmers' initiatives. Although their approach allows a qualitative evaluation of consequences of farmers' responses to ecosystem services, further linkages of agents and spatial scenario analyses are required to assess the impact of land use change and management practices on the provision of ecosystem services.

Fleskens et al. examine how individual land users' responses to an alteration in the provision of freshwater play out at the level of the regional economy of the Murcia autonomous region in Spain. To this end, they combine discrete choice-based scenarios and a regional input-output model extended with water budget accounting. Partially building on the work from Nainggolan et al., they show that although water taxation has minor effects on product prices it can easily lead to dramatic land use changes with considerable economic impact. Smart taxation may provide an incentive to mobilize a certain self-organizing capacity of the agricultural sector to deal with some of its water use inefficiency. Continued provision of freshwater through inter-basin water transfer benefits the economy but increases its dependence on water, hence increases regional vulnerability to climate change. A moderate reduction in water use in the economy will benefit areas of ecological importance and might replenish some of the depleted groundwater resources, which could be crucial to prepare for future environmental change. 
The second group of papers explicitly reports on the use of models to design PES schemes. Frequently, choice experiments (or choice modelling), a widely used stated preference elicitation method, are used to inform models about stakeholder valuation of-or willingness to pay forecosystem services.

Beharry-Borg et al. (2013) investigate the potential use of a PES scheme financed by a water company to incentivize farmers to adjust their agricultural land management practices to protect water quality. The rationale behind such a scheme being that it might be more cost-effective to take preventive action rather than treatment, while at the same time fulfilling the requirements of the European Water Framework Directive. The authors use latent class analysis of farmers' CE responses to quantify the size and spread of farmers' preferences for compensation payments and potential drivers of preference variation. These types of analyses can provide useful information for beneficiaries of ecosystem services on preferences of farmers and their willingness to adjust some of their practices to deliver ecosystem services at least cost. In the North Yorkshire (UK) case study, considerable variability in willingness to accept for changes in management practices was found, triggering the question whether the spatial configuration of potential participants would be conducive to producing impacts at the catchment level.

Drake et al. (2013) use choice experiments to elicit the additional compensation required for local versus nationally dispersed mitigation actions, such as planting trees for carbon sequestration either locally or nationally and filling in drainage ditches upstream to reduce flood risk. The research design and analysis are specifically focusing on investigating notions of NIMBYism and altruism. Their results show that both appreciation differentiation processes exist and could be used by policy makers in plans of where to implement mitigation actions. Altruism was especially found where enhanced regulating ecosystem services would benefit clearly identifiable downstream communities - that is, in the case of flood risk reduction. NIMBYism occurred where global regulating ecosystem services did not benefit a clearly identifiable community, and where the necessity to act locally was not obvious to respondents.

In the final paper, Balderas Torres et al. (2013) similarly relate contingent valuation of willingness to reduce carbon emissions at household level with a wide range of household attributes, including socio-economic conditions, environmental awareness, risk perception and ethical/citizenship attitudes. Their findings show differentiation of willingness to pay for conservation of the local La Primavera Biosphere Reserve in Guadalajara (Mexico) triggered by different levels of perceived co-benefits derived from the forest by respondents. This proximity element requires further study. Regarding global benefits, the authors find important influence of the mode of surveying used: market stall interviews, with the benefit of personal interaction, lead to higher willingness to pay for climate change mitigation than internet-based surveys. From this, it is clear that carbon markets might function better if implemented with sensitization programmes to instigate greater sense of responsibility among carbon emitters.

The papers in this special section show that land management importantly influences the provision of ecosystem services and that this is also recognized by the general public. Ex post studies of the impact of land management on ecosystem services have the benefit of a larger evidence base, but can only offer generic recommendations for policies. Increased understanding of the dynamics driving environmental change (e.g. zonal differentiations or market conditions) is crucial in order to guide interventions. When it comes to ex ante studying the impacts of land management on ecosystem services, hypothetical scenarios need to be presented to actors (providers or beneficiaries of ecosystem services). Different methods exist and have been applied from the perspective of land management and demand or supply side of ecosystem services. Applications of these methods have generated important insights into stratification factors. Understanding the impacts of such variations on complex human-environment interactions is the key to inform decisions concerning adaptation to and mitigation of environmental change. However, equally important is an understanding of the qualities and limits of scientific methods of enquiry in this domain. The papers bundled here offer contributions to both empirical evidence and methodological advancements and will hopefully inspire further thought and action.

\section{References}

Balderas Torres A, MacMillan DC, Skutsch M, Lovett JC (2013) The valuation of forest carbon services by Mexican citizens: the case of Guadalajara city and La Primavera biosphere reserve. Reg Environ Change. doi:10.1007/s10113-012-0336-z

Beharry-Borg N, Smart JCR, Hubacek K, Termansen M (2013) Evaluating farmers' likely participation in a payment programme for water quality protection in the UK uplands. Reg Environ Change. doi:10.1007/s10113-012-0282-9

Brown TC, Bergstrom JC, Loomis JB (2007) Defining, valuing, and providing ecosystem goods and services. Nat Resour J 47: 329-376

DeFries R, Foley J, Asner G (2004) Land-use choices: balancing human needs and ecosystem function. Frontiers Ecol Environ 2:249-257

Drake B, Smart JCR, Termansen M, Hubacek K (2013) Public preferences for production of local and global ecosystem services. Reg Environ Change. doi:10.1007/s10113-011-0252-7

Fleskens L, Nainggolan D, Termansen M, Hubacek K, Reed MS (2013) Regional consequences of the way land users respond to future water availability in Murcia, Spain. Reg Environ Change. doi:10.1007/s10113-012-0283-8 
Goldman RL, Tallis H, Kareiva P, Daily GC (2008) Field evidence that ecosystem service projects support biodiversity and diversify options. Proc Natl Acad Sci USA 105:9445-9448

Hubacek K, Kronenberg J (2013) Synthesizing different perspectives on the value of urban ecosystem services. Landscape Urban Plan 109:1-6

Hubacek K, Beharry N, Bonn A, Burt T, Holden J, Ravera F, Reed M, Stringer L, Tarrasón D (2009) Ecosystem services in dynamic and contested landscapes: the case of UK uplands. In: Winter M, Lobley M (eds) What is land for? The Food, Fuel and Climate Change Debate, Earthscan, pp 167-188

Millennium Ecosystem Assessment (MA) (2005) Ecosystems and human well-being: synthesis. Island Press, Washington

Mauerhofer V, Hubacek K, Coleby A (2013) From polluter pays to beneficiary pays: distribution of rights and costs under payments for ecosystem services. Ecol Soc (forthcoming)

Nainggolan D, Termansen M, Hubacek K, Reed MS (2013) An integrated modelling approach for evaluating land use change in a degradation prone agro-ecosystem of southern Spain. Reg Environ Change. doi:10.1007/s10113-011-0261-6
Pagiola S, Platais G (2007) Payments for environmental services: From theory to practice. The World Bank, Washington

Qasim M, Hubacek K, Termansen M, Fleskens L (2013) Modelling land use change across elevation gradients in district Swat, Pakistan. Reg Environ Change. doi:10.1007/s10113-012-0395-1

Van de Sand I (2012) Payments for ecosystem services in the context of adaptation to climate change. Ecol Soc 17(1):11. doi: 10.5751/ES-04561-170111

Wunder S (2005) Payments for environmental services: some nuts and bolts. Occasional paper 42. CIFOR, Bogor, Indonesia

Wunder S, Engel S, Pagiola S (2008) Taking stock: a comparative analysis of payments for environmental services programs in developed and developing countries. Ecol Econ 65:834-852

Yeo I, Huang C (2013) Forest dynamics in Mississippi, USA: a hybrid statistical and geospatial analysis. Reg Environ Change. doi: 10.1007/s10113-012-0340-3 